\title{
Rolf Maximilian Sievert (1896-1966): father of radiation protection
}

\author{
Masaru Sekiya $^{1} \cdot$ Michio Yamasaki $^{2}$
}

Published online: 29 July 2015

(C) Japanese Society of Radiological Technology and Japan Society of Medical Physics 2015

\section{Members of the Sievert family}

Rolf Maximilian Sievert's father, Max Sievert (1849-1913), was the eldest son of Heinrich Theodor Sievert, who served as the chairman of the town council in Zittau, East Germany (near the border of Czechoslovakia). After completing the compulsory education of the time, Max often visited Russia and Northern European countries for business purposes while working for an agency that specialized in the handling of machines. He felt that acting as an interface between Germany and Sweden through trading would surely lead him to success and established the Max Sievert Company in Stockholm in 1881, specializing in the wholesale trade of machines. The company not only imported German machines and tools, but expanded by exporting products manufactured in Sweden. The company grew substantially by producing telephone cables in Sweden and became the Max Sievert Manufacturing Co. Ltd. Max obtained Swedish citizenship in 1885 and married Sofia Carolina Panchéen in 1894. Their daughter, Lisa, was born in 1895, and son Rolf Sievert was born on May 6, 1896. The children grew up comfortably. Max died in 1913 when Sievert was 17 years old. Sievert inherited an enormous fortune from his father, enough so that he could live a comfortable life on the interest alone.

Masaru Sekiya

mseki@clg.niigata-u.ac.jp

1 Department of Radiological Technology, Graduate School of Health Sciences, Niigata University, 2-746 Asahimachi-dori, Chuo-ku, Niigata 951-8518, Japan

2 Hokkaido University, 2665-7 Toxtupara, Nishi-ku, Niigata 950-1115, Japan

\section{Education}

In 1914, Rolf Sievert took the high school graduation examination at Nya Elementarskolan, an experimental school providing education based on a new teaching methodology. However, Sievert was not particularly serious about education. In the autumn of 1914, he began to study medicine at the Karolinska Institute, but lost interest in his studies and soon stopped. Confused as to what to do, Sievert finally decided to take the test for the Kungliga Tekniska Högskolan (KTH: the Royal Institute of Technology).

Because of his extremely poor results at Nya Elementarskolan, Sievert had to take a high school graduation supplementary examination for mathematics, physics, and chemistry in the spring of 1915. Since he had started fresh with a sense of purpose this time, there was a considerable improvement in his results. In the autumn of 1915, he was admitted to KTH's Faculty of Electrical Engineering. However, he dropped out of the school because the lectures were too complex for him.

Finally, between 1915 and 1917, Sievert started studying for the bachelor's examination at Uppsala University. He passed it in 1919, with astronomy, meteorology, mathematics, and mechanics as special subjects. Uppsala University was the top physics school in Sweden and led the academic world in physics. Notably, Professor Carl Wilhelm Oseen used to lecture at the university about theoretical physics in the field of meteorology, presenting the topic in a simple manner. Sievert studied mechanics for 1 year under Professor Oseen. This greatly helped to shape Sievert's later career as a scholar.

After completing his studies at Uppsala University, Sievert returned to Stockholm, where he was employed at the Royal Swedish Academy of Sciences as an assistant. In 
1919, he started studying for the master's examination in physics at Stockholm College.

\section{Encounter with radiation physics}

In the summer of 1920, Sievert visited the United States to observe the progress in new fields in physics. At the same time, Gösta Forssell of the Radiumhemmet ${ }^{1}$ was also in the United States conducting research on medical radiology. Forssell and Sievert, who keenly felt the need for teamwork in medical radiology and physics, met by coincidence at the Center for Radiological Research in Schenectady, New York. After developing a rapport with each other, the two decided to visit various places across the United States for observation, beginning the next day. After visiting Dr. Gioacchino Failla ${ }^{2}$ at the Memorial Hospital in New York, Sievert learned the method for regulating radium emanation (technically known as "radon" in radiation therapy) proposed by William Duane of Harvard University.

When he returned to Sweden, Sievert found support at the Radiumhemmet to start basic work on the measurement of radiation. In 1921, he carried out measurements on the spatial distribution of radiation from various radium compounds and mathematically calculated the intensity of radiation from radium compounds arranged simultaneously along a line, in the form of rings, and on a plane (Sievert integration theory). He also emphasized radiation protection and the need to limit professionals' exposure to radiation.

After obtaining a master of science degree in 1924, Sievert started formal collaborative research with Forssell of the Radiumhemmet. He had the status of a full-time researcher, but without any remuneration. As there was only a small physics laboratory in the Radiumhemmet, he donated a physics laboratory. He also donated large sums for the procurement of instruments and equipment and for their maintenance expenses. That year, Sievert became the first director of the physics laboratory.

\footnotetext{
${ }^{1}$ Radiumhemmet: John Berg (surgeon), Gösta Forssell (radiotherapist), et al. opened a cancer treatment clinic in Kungsholmen in Stockholm by collecting private funds. It was named the Radiumhemmet in 1910. The Radiumhemmet was equipped with 16 beds, an X-ray machine, and a radium appliance. The Radiumhemmet was under the management of the Stockholm Cancer Association. Translated by Michio Yamasaki: Life of Sievert, p. 14, Kokodo Shoten (Niigata), 1994

${ }^{2}$ Gioacchino Failla: Pioneer of biophysics and radiobiology in the United States. From early on, he was engaged in research on medical applications of radiology. He was a member of the National Council on Radiation Protection (NCRP) and also contributed to the founding of the International X-ray and Radium Protection Committee (IXRPC).
}

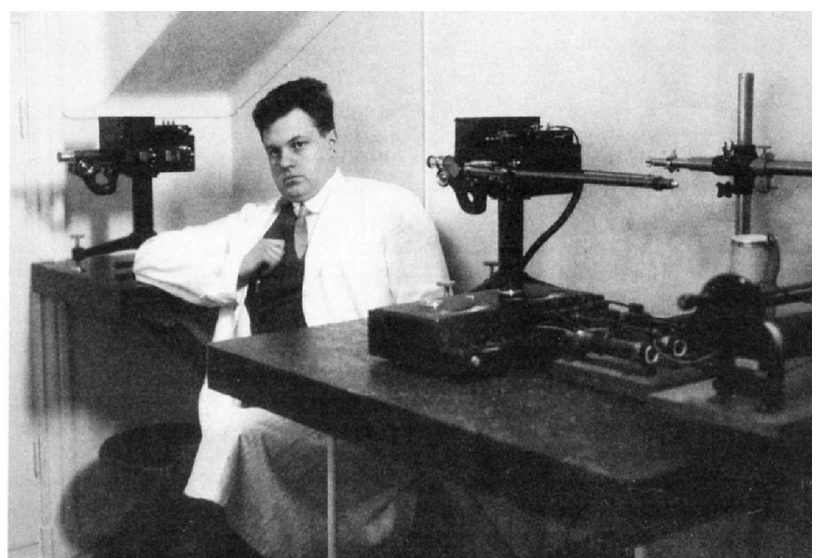

Sievert in the physics research laboratory in the Radiumhemmet. Taken from p.7 of Ref. [1]

The mobile measurement division of the physics laboratory started in 1925 with a portable dosimeter that was carried during patrolling visits for measurement of the tube voltage, tube current, and dose rate for a fee, and also the division resolved a series of problems at the sites. The mobile division helped Swedish hospitals and hospitals in other parts of Northern Europe handle radium and the measurement of radiation. In 1926, Sievert succeeded in standardizing the skin erythema dose and made a capacitortype dosimeter, called a Sievert chamber. In 1928, he developed a filter for deep X-ray therapy (the Thoraeus filter). In that year, during the Second International Congress of Radiology held in Stockholm, Sievert played the central role in the discussion on the adoption of the roentgen as the international unit and in recommendations for protecting medical radiology practitioners from radiation. $^{3}$

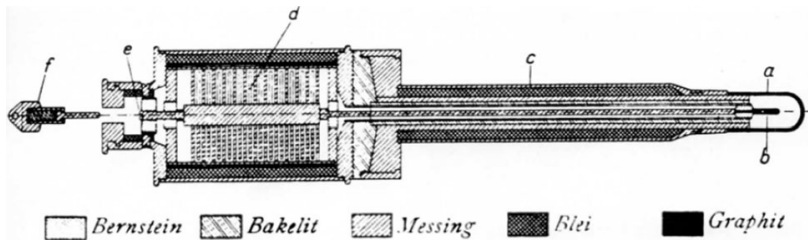

External view of the Sievert chamber. Taken from Weinberger and Yamasaki 1994, p. 50

\footnotetext{
3 In 1921, Sievert proposed the Intensity Curie (Ic) as the unit of intensity of gamma rays, and in the early 1930s, he proposed the Intensity Roentgen (Ir: roentgen intensity), a unit that was a new concept. Translated by Michio Yamasaki: Life of Sievert, p. 52, Kokodo Shoten (Niigata), 1994.
} 


\section{Contributions toward radiotherapy technique, radiobiology, and radiation protection laws}

In 1929, Sievert proposed a radium compensator as a tool for measurement of the radium therapy and the radium remote-exposure method. Furthermore, he used a new construction material (iron ore concrete) as a radiation shield for the walls of remote radiation chambers and succeeded in reducing the thickness of the walls to half that of conventional walls. Various kinds of capacitor-type dosimeters were prepared. For example, a small, lightweight, and strong capacitor case could be introduced into a body cavity and could be implanted directly into position for irradiation. It was also possible to measure the distribution of the dose in a water phantom. This contributed greatly to protecting therapists from radiation and also improved the radiotherapy technique.

Sievert later accomplished many other things at the Radiumhemmet. In 1932, he received a doctorate degree from Uppsala University. He also became a lecturer in medical physics at Stockholm College.

In 1938, the Radiumhemmet's physics laboratory came under the administration of the Karolinska Hospital (Karolinska sjuhuset), ${ }^{4}$ and its name was changed to the Radiation Physics Research Institute. Sievert became its head and was appointed as professor of radiation physics in the research division of the Karolinska Hospital in 1941. The Radiation Physics Research Institute affiliated with the Karolinska Hospital was established in order to meet the requirement of specialized knowledge of physics and biophysics for use in radiation therapy, X-rays, and radioactive substances. In 1941, the research institute came under government management and became the Radiation Physics Research Division of the present Karolinska Institute.

In 1925, Italy established the world's first radiation protection law for practitioners working in radiotherapy establishments and also for patients. Sweden was another country that enforced regulations on radiation protection quite early, in 1941. France and Germany also enacted laws related to $\mathrm{X}$-rays and accompanying protection measures. Sievert had worked on radiation protection for

\footnotetext{
4 The Karolinska Hospital is an affiliated body of the Karolinska Institute. The Karolinska Research Institute (also known as Karolinska Medical University) is the largest medical college in Europe. The selection committee for the Nobel Prize in Physiology or Medicine was established by this institute in 1901 .
}

Sweden since 1928 and had drafted a radiation protection law concerning radiation work in collaboration with radiologists. The radiation protection law was bestowed extremely high academic authority in the Radiation Physics Research Institute. The radiation protection law made it mandatory to submit a report on X-ray machines or radioactive isotopes such as radium, a past history of the person in charge, and a medical-examination report on any disorders in the radiation practitioner. The radiation physics research institute not only supervised reports and performed inspection duties, but also conducted scientific research in important fields such as radiation physics, biophysics, and the implementation of laws.

When the Second World War ended in 1945, the Radiation Physics Research Institute was in the process of returning to its original duties. However, it had a shortage of staff due to the inspection work, and this often hindered daily research activities. The human body contains a small amount of radium by nature, and Sievert was interested in measuring it. In collaborative research with British physicist Frederick W. Spiers, he demonstrated that ${ }^{40} \mathrm{~K}$, which accounts for $0.012 \%$ of the total potassium present in the body, is the main source of radioactivity in the human body. Furthermore, Sievert did pioneering research related to the measurement of radon inside a building and radiation doses to the lungs, in collaboration with young scientists of the Radiation Physics Research Institute.

\section{Activities in the international scenario}

With the increasing use of X-rays during and after the First World War, hematologic diseases occurred frequently among the professionals handling X-rays, and there was a great increase in the number of deaths. This started discussion on the need for radiation protection. By the mid1920 s, radiation was considered hazardous, and serious discussions about trials for determining tolerable doses began.

During the First International Congress of Radiology, held in London in 1925, Britain made a motion for a debate on the need for a recommendation related to radiation protection and the establishment of an international unit for radiation. However, as no conclusion was reached, this became an assignment for the Second International Congress of Radiology held 3 years later in Stockholm. A study group was formed, and Sievert was to play the central role in it. Radiumhemmet's radiation physics laboratory staff was snowed under during 1927-1928 with preparations for the international congress. 


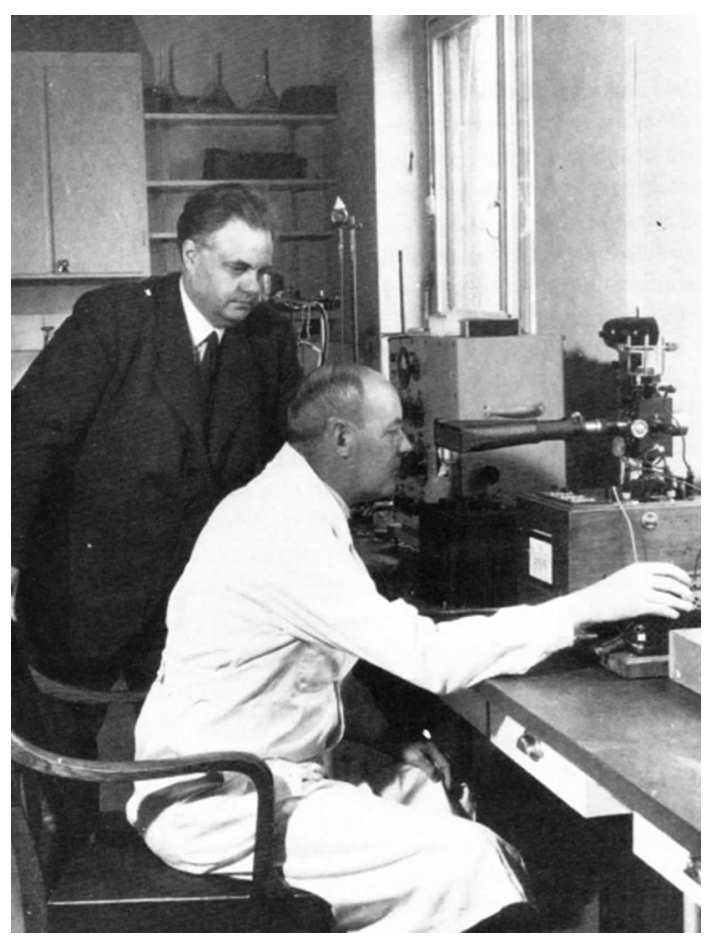

Sievert in the laboratory. Taken from Weinberger and Yamasaki 1994, p. 180

The Second International Congress of Radiology, held in July 1928, concluded with great success. During the congress, it was decided to establish the International X-ray and Radium Protection Committee (IXRPC), the predecessor of the present International Commission on Radiological Protection (ICRP), to study problems related to protection from X-rays, and also to study internationalization of the unit of X-rays. Not surprisingly, Sievert was a member and was selected as the chairman of the committee. Beginning in 1928, Sievert's activities were noticed in the international arena.

The ICRP, which met in Zurich in 1934, prescribed the dose limit for the first time. Its objective was to avoid nonstochastic (definitive) radiation hazards, and the dose was denoted by a new unit: the Roentgen $\{R\}$. Sievert gave a comprehensive lecture, "On Nature's gamma rays," and reported the results of a survey that indoor gamma rays are high. In 1935, after conducting experiments on growing Drosophila melanogaster by shielding the flies from natural radiation, he discovered that their growth is extended at a low level of radiation. However, he had to suspend this work because of the Second World War.

In 1956, Sievert was elected as the chairman of the ICRP (1956-1962). Sievert abolished the conventional subcommittees and started fresh with a main committee and four subcommittees, 60 members in all. The four special committees were established for biological effects of radiation, internal exposure, external exposure, and committee recommendations. This change clarified the objectives to be discussed by the committees. In November 1956, the United Nations Scientific Committee on the Effects of Atomic Radiation (UNSCEAR) sought cooperation from ICRP and ICRU to prepare a report for the United Nations on the subject of how to stipulate reliable data concerning the dose to various organs of the human body, particularly the reproductive glands, and the average dose for people in general during an X-ray examination. Sievert served as the chairman of UNSCEAR from 1958 to 1960 , and in these 2 years he held topmost posts in two international radiation protection committees, including the ICRP.

\section{Measures against nuclear accidents}

In 1950, Sievert prepared an instrument for the continuous measurement of natural gamma rays. Around 1955, Sievert remodeled a bus by mounting a radiation-measuring instrument on it and started preparing a map of radiation distribution in Sweden. Furthermore, he surveyed the radioactivity of moss by using special instruments mounted on an aircraft. While taking a ship to the United States, Sievert mounted a radiation counter on the bridge and confirmed that the dose of natural radiation varies with changes in the earth's magnetic field.

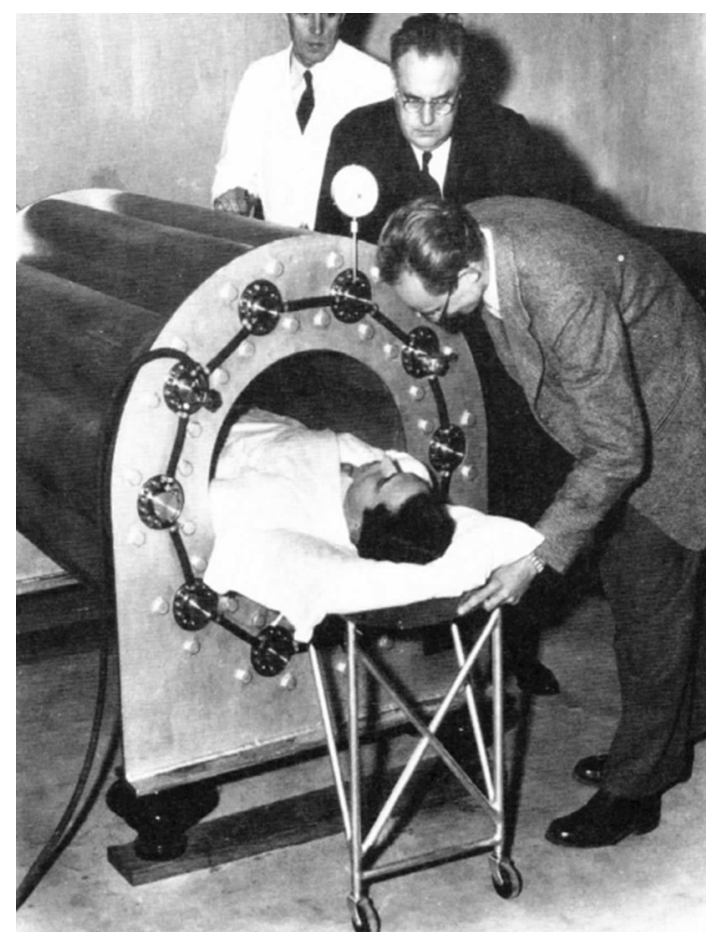

Sievert during the trial run of the whole-body measuring instrument. Taken from Weinberger and Yamasaki 1994, p. 101 
In 1957, the world's first atomic reactor accident occurred in Windscal (Britain), which is a large-scale nuclear power plant. After the disaster, a program with a number of measures against atomic reactor accidents was prepared in England. The Medical Research Council of Britain played the key role in developing the program. In 1957 in the United States, measures against major nuclear accidents were announced in the Brookhaven Report by the United States Atomic Energy Commission. In July 1960, the Swedish government established a special committee, Expertkomission for radigivning vid atomolyckor (KRA), for deliberations about measures to be taken at the time of an atomic reactor accident and to give suitable advice. Sievert, along with radiation physics researchers, participated as a member of the Special Committee. Sievert set up a radiation counter near Agesta, where Sweden's first commercial nuclear power plant was situated, and via telephone he made arrangements to monitor radiation levels from the Radiation Physics Research Institute. After the KRA was established, the Soviet Union announced its nuclear weapon explosion experiment on the island of Novaja Zemlja, northeast of Kolahalvon (Kola Peninsula).

In 1961, Sievert began to prepare a unique plan of fallout-treatment measures to be taken if an accident befell Sweden, including transmitting information to citizens in surrounding areas or communicating with neighboring countries. Fortunately, no incidents occurred at that time. In the 1960s, several special meetings about radiation protection in Northern Europe were held, and Sievert was at the center stage. In 1963, even after the enactment of the Limited Test Ban Treaty, Sievert spent a great deal of time on radiation protection.

\section{His last days}

Sievert held important posts such as chief officer of the Sweden Physics Committee (1941-1945), member of the Defense Research Committee (1943-1945), member of the Royal Science Academy (1944), chief officer of Sweden's Cancer Institute (1945), chairman of the Cancer Research Committee (1946), honorary member of the British Radiology Society (1948), and vice-chairman of the North Norrland Science Academy Research Facility (1952). Furthermore, he received many domestic and international awards for his accomplishments, including the 3rd Order of Merit North Star Medal (1945) and the Science Academy
Award Linne gold medal for his role in the establishment of the Kiruna Geophysics Observation Station (1957) [2]. ${ }^{5}$

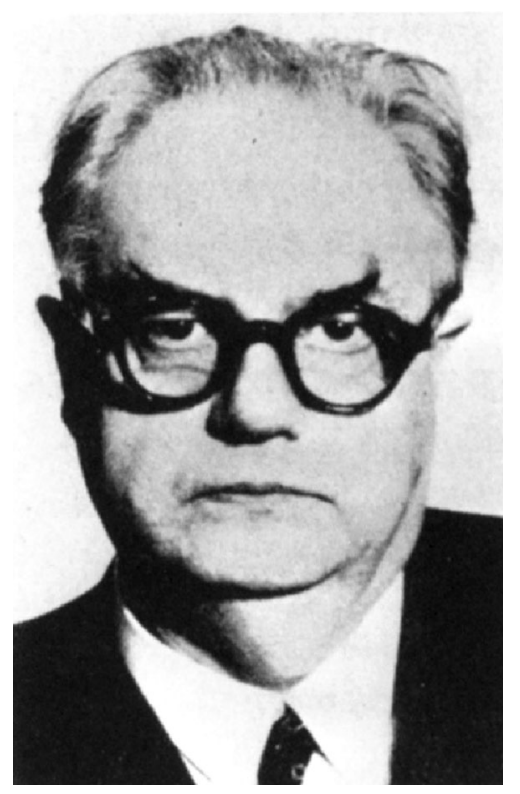

Sievert in his last days. Taken from Ref. [1]

In 1965, Sievert resigned from all of his positions. He wanted to devote time to work on government institutions, write an introductory book on radiation protection, and enjoy a leisurely retired life. He was admitted to the Karolinska Hospital for gastric cancer surgery on December 1, 1966, and initially the surgery was thought to be successful. However, 2 days after the surgery, there was a complication of a pulmonary thromboembolism, and Sievert suddenly left this world. He died on December 3, 1966, at the age of 70 .

In honor of Sievert's lifetime achievements, the ICRP prescribed a unit for the dose of radiation affecting the human body (equivalent dose) as the Sv (Sievert) in 1979.

\section{References}

1. Yamasaki M. Sievert and Becquerel-Person and achievement. Niigata: Daikisha; 2012. p. 1-70.

2. Hans W (Author), Yamasaki M (Translator). Life of Sievert-the father of radiation protection. Niigata: Kokodo Shoten; 1994.

\footnotetext{
$\overline{5 \text { Translated }}$ by Michio Yamasaki: Life of Sievert, pp. 190-191, Kokodo Shoten (Niigata), 1994.
} 